\title{
A liquid crystal-related compound induces cell cycle arrest at the G2/M phase and apoptosis in the A549 human non-small cell lung cancer cell line
}

\author{
TAKUYA WAKASAYA ${ }^{1}$, HIRONORI YOSHINO $^{1}$, YUKAKO FUKUSHI ${ }^{2}$, \\ ATSUSHI YOSHIZAWA $^{2}$ and IKUO KASHIWAKURA ${ }^{1}$
}

${ }^{1}$ Department of Radiological Life Sciences, Division of Medical Life Sciences, Hirosaki University Graduate School of Health Sciences, Hirosaki, Aomori 036-8564; ${ }^{2}$ Department of Frontier Materials Chemistry, Graduate School of Science and Technology, Hirosaki University, Hirosaki 036-8561, Japan

Received June 27, 2012; Accepted August 20, 2012

DOI: 10.3892/ijo.2013.1804

\begin{abstract}
Liquid crystals are the state of matter existing between liquid and crystalline phases, and recently there has been increasing interest in their biological effects. Following our recently reported work, we investigated the cell suppressive effects of liquid crystal-related compounds (LCRCs), which are precursors of liquid crystals, in the human non-small lung cancer cell line A549. We found that 2-(4-butoxyphenyl)5-(4-hydroxyphenyl)pyrimidine (LCRC-1) dramatically suppressed cell growth. Treatment with $12 \mu \mathrm{M}$ LCRC-1 for $12 \mathrm{~h}$ induced cell cycle arrest at the G2/M phase. Furthermore, LCRC-1 increased the sub-G1 fraction and Annexin V-positive cells and activated caspase-3 in A549 cells, which showed that it can induce apoptosis in these cells. Furthermore, because the induction of apoptosis by LCRC-1 was partly inhibited by treatment with pan-caspase inhibitor, it appeared that LCRC-1 induced apoptosis by a caspase-dependent pathway. The ability of LCRC-1 to cause DNA damage was assessed, but LCRC-1 did not induce expression of $\gamma-\mathrm{H} 2 \mathrm{AX}$, which is a marker of DNA damage. Treatment with LCRC-1 did not inhibit the proliferation of WI-38 normal fibroblast cells, which makes the tumor-specific suppressive effect of LCRC-1 attractive for its application as a new antitumor drug.
\end{abstract}

\section{Introduction}

Clinical cancer therapy includes the use of most common treatments such as surgery, radiation and chemotherapy for

Correspondence to: Dr Ikuo Kashiwakura, Department of Radiological Life Sciences, Division of Medical Life Sciences, Hirosaki University Graduate School of Health Sciences, 66-1 Hon-cho, Hirosaki, Aomori 036-8564, Japan

E-mail: ikashi@cc.hirosaki-u.ac.jp

Key words: liquid crystal-related compounds, apoptosis, G2/M arrest, A549 cells cancer patients. Chemotherapeutic agents can regulate uncontrolled proliferation of abnormal cancer cells and are often combined with surgery and/or radiation therapy. The majority of chemotherapeutic drugs can be classified as alkylating agents, antimetabolites, anthracyclines, plant alkaloids, topoisomerase inhibitors, monoclonal antibodies, and other antitumor agents (1-4). Numerous studies are progressing to develop antitumor drugs such as molecular-targeting drugs although few drug therapies lead to complete recovery in cancer patients $(5,6)$. Therefore, the development of more effective chemotherapeutic drugs is essential for the treatment of cancer.

Liquid crystal is the state of matter existing between liquid and crystalline phase and is characterized by the partial or complete loss of positional order of the constituent molecules (7). Liquid crystal compounds (LCCs) are widely used in display media such as in television screens. In general, liquid crystals are synthesized from various precursors such as a flexible chain, a rigid aromatic core, and hydrophobic and hydrophilic units. In contrast, various biological cell structures such as cell membranes consist of amphiphilic phospholipids. Therefore, LCCs or their precursors, namely liquid crystalrelated compounds (LCRCs), possibly interact with biological cell structures. In fact, there has been an interest in the biological and pharmacological effects of these compounds (8-10).

We previously demonstrated that LCCs suppressed the cell growth of the non-small cell lung cancer (NSCLC) cell line A549 through G1-phase arrest, although it did not induce cell death (11). Recently, we also reported that some LCRCs dramatically suppressed cell growth and induced apoptosis in human chronic myelogenous leukemia K562 cells (12). Although leukemic cells are more sensitive to chemotherapy and ionizing radiation compared with solid malignancies (13), there is a possibility that these LCRCs potentially suppress cell growth and induce cell death in solid malignancies including NSCLC. Therefore, in the present study, we investigated the antitumor effect of LCRCs in the NSCLC cell line A549. Furthermore, the radiosensitization effect of LCRC was also examined because combined treatment with radiotherapy and chemotherapy has been extensively used in the management of many types of solid malignancies including NSCLC. 


\section{Materials and methods}

Reagents. The structures of LCRCs used in the present study are shown in Fig. 1. The compounds 2-(4-butoxyphenyl)-5-(4-hydroxyphenyl)pyrimidine (LCRC-1) and2-\{4-(4-hexyloxyphenyl) phenyl\}-5-hydroxypyrimidine (LCRC-2) were purchased from Midori Kagaku Co Ltd. (Tokyo, Japan). Each compound was dissolved in pure dimethyl sulfoxide (DMSO) (Sigma-Aldrich, St. Louis, MO, USA). A pan-caspase inhibitor, benzyloxycarbonyl-Val-Ala-Asp fluoromethyl ketone (Z-VAD-FMK), was purchased from Promega Co Ltd. (Madison, WI, USA). Propidium iodide (PI) was purchased from Sigma-Aldrich.

Cell culture. Human lung cancer cell A549 and normal fibroblasts called human embryonic fibroblast, lung-derived cell line (WI-38) were purchased from the RIKEN Bio-Resource Center (Tsukuba, Japan). The A549 cells were maintained in Dulbecco's modified Eagle's medium (DMEM, Sigma-Aldrich) supplemented with $10 \%$ heat-inactivated fetal bovine serum (FBS, Japan Bioserum Co. Ltd., Japan) at $37^{\circ} \mathrm{C}$ in a humidified atmosphere containing $5 \% \mathrm{CO}_{2}$. The WI-38 cells were maintained in Minimum Essential Medium Eagle (MEM, Sigma-Aldrich) supplemented with $10 \%$ heat-inactivated FBS at $37^{\circ} \mathrm{C}$ in a humidified atmosphere containing $5 \% \mathrm{CO}_{2}$.

Liquid culture. The A549 cells $\left(6.0 \times 10^{4}\right)$ were seeded onto a 35-mm culture dish (Iwaki, Chiba, Japan) and cultured overnight to allow adherence to the dish. Next day, each compound $(12 \mu \mathrm{M})$ or vehicle (DMSO) was added in the culture medium and cultured for 3 days. After 3-day culture, the cells were harvested with $0.1 \%$ trypsin-EDTA (Gibco ${ }^{\circledR}$ Invitrogen, CA, USA) and viable cells were counted by trypan blue exclusion assay. To investigate the effect of LCRC-1 in detail, the A549 cells were treated with 1.5-12 $\mu \mathrm{M}$ LCRC-1 for $72 \mathrm{~h}$ and then the viable cells were counted as described above.

Cell cycle analysis by flow cytometry. The A549 cells were seeded onto a 60-mm culture dish (Iwaki) and incubated overnight to adhere to the dish. The cells treated with the compound were harvested and fixed with $70 \%$ ethanol overnight at $4{ }^{\circ} \mathrm{C}$. The fixed cells were washed with PBS(-) and then treated with RNase $(200 \mu \mathrm{g} / \mathrm{ml})$ at $37^{\circ} \mathrm{C}$ for $30 \mathrm{~min}$ to hydrolyze RNA. After treatment, the cells were washed with PBS(-) and stained with PI $(25 \mu \mathrm{g} / \mathrm{ml})$ for $30 \mathrm{~min}$ in the dark. A flow cytometer (Cytomics FC500, Beckman-Coulter, Fullerton, CA, USA) was used to analyze the cell cycle distribution.

Detection of apoptosis. The extent of apoptosis was determined by Annexin V-FITC (BioLegend, San Diego, CA, USA) and PI staining according to the manufacturer's instructions. Briefly, the cells treated with compound were harvested, washed, and suspended in the binding buffer $(10 \mathrm{mM}$ HEPES/ $\mathrm{NaOH}$, $140 \mathrm{mM} \mathrm{NaCl}, 2.5 \mathrm{mM} \mathrm{CaCl}_{2}, \mathrm{pH}$ 7.4). The Annexin V-FITC $(2.5 \mu \mathrm{g} / \mathrm{ml})$ and PI solution $(50 \mu \mathrm{g} / \mathrm{ml})$ were added in the cell suspension and incubated for $15 \mathrm{~min}$ at room temperature in the dark. Apoptosis cells were determined by flow cytometry. In the Annexin V/PI quadrant gating, Annexin $\mathrm{V}(-) / \mathrm{PI}(-)$, Annexin $\mathrm{V}(+) / \mathrm{PI}(-)$, and Annexin $\mathrm{V}(+) / \mathrm{PI}(+)$ were used to identify the fraction of viable cells, early apoptotic cells, and late apoptotic/necrotic cells, respectively.
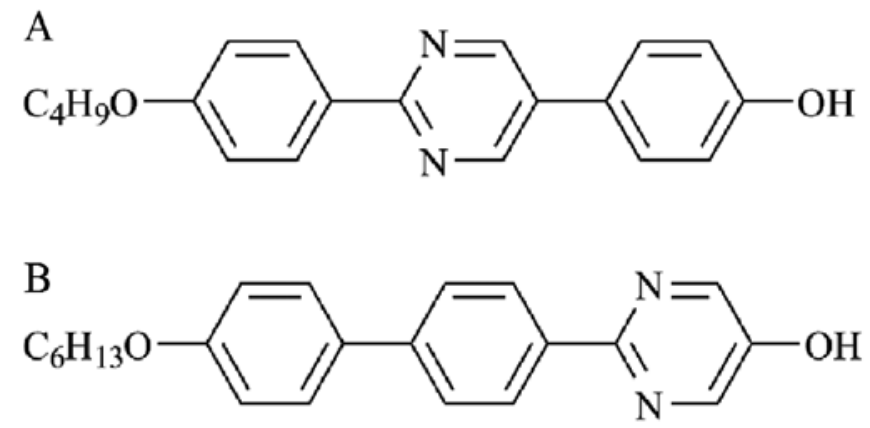

Figure 1. Structural formulas of the liquid crystal-related compounds (LCRCs) used in this study. (A) 2-(4-butoxyphenyl)-5-(4-hydroxyphenyl)pyrimidine (LCRC-1); (B) 2-\{4-(4-hexyloxyphenyl)phenyl $\}-5$-hydroxypyrimidine (LCRC-2).

Detection of activated caspase-3. An FITC-conjugated monoclonal active caspase-3 antibody apoptosis kit (BD Biosciences, San Diego, CA, USA) was used to detect active caspase-3 according to the manufacturer's instructions. Briefly, the cells treated with compound were harvested and washed with PBS(-). The cells were suspended in Cytofix/Cytoperm ${ }^{\mathrm{TM}}$ and incubated for $20 \mathrm{~min}$ on ice. After incubation, the cells were washed with Perm/Wash ${ }^{\mathrm{TM}}$ buffer and resuspended in Perm/Wash ${ }^{\mathrm{TM}}$ buffer containing 5\% FITC-conjugated antiactive caspase- 3 antibody. After $30 \mathrm{~min}$ incubation at room temperature in the dark, the cells were washed and then analyzed by flow cytometry.

Inhibition of caspase by Z-VZD-FMK. The A549 cells were preincubated with $100 \mu \mathrm{M}$ Z-VAD-FMK, a pan-caspase inhibitor, for $1 \mathrm{~h}$ before adding to the compound. After $48 \mathrm{~h}$ culturing in the presence of compound, the cells were harvested and the viable cells were counted. Furthermore, the analysis of apoptosis (Annexin V-FITC and PI staining) and detection of active caspase-3 were performed as described above.

Immunofluorescence detection of $\gamma-H 2 A X$. The A549 cells $\left(3.0 \times 10^{4}\right)$ were grown on chamber slides II (Iwaki) overnight to allow adherence to the slides. After treatment with compound for the indicated periods, the cells were fixed with cold methanol for $20 \mathrm{~min}$ and acetone for $7 \mathrm{sec}$, dried, treated with $0.5 \%$ Triton X-100 (Wako, Osaka, Japan) for $10 \mathrm{~min}$, and washed in PBS(-). The cells were then incubated with anti-phospho-histone H2AX monoclonal antibody (JBW301, Upstate Biotechnology, Lake Placid, NY, USA) at a 300-fold dilution with TBST (20 mM Tris-HCl, pH 7.4, $137 \mathrm{mM} \mathrm{NaCl}$, $0.1 \%$ Tween-20) containing 5\% skim milk for $60 \mathrm{~min}$ at room temperature. After the cells were washed with PBS(-), they were then incubated with an AlexaFluor $488^{\circledR}$ conjugated antimouse immunoglobulin G second antibody (Molecular Probes, Eugene, OR, USA) at a 400-fold dilution with TBST containing 5\% skim milk for $60 \mathrm{~min}$ at room temperature, and washed in PBS(-). The slides were stained and mounted with Vectashield ${ }^{\circledR}$ Mounting Medium with DAPI (Vector Laboratories Inc., Burlingame, CA, USA). Photographs of the cells were taken with a Laser Scanning Microscope 710 (Carl Zeiss Microscopy Co Ltd., Tokyo, Japan). 

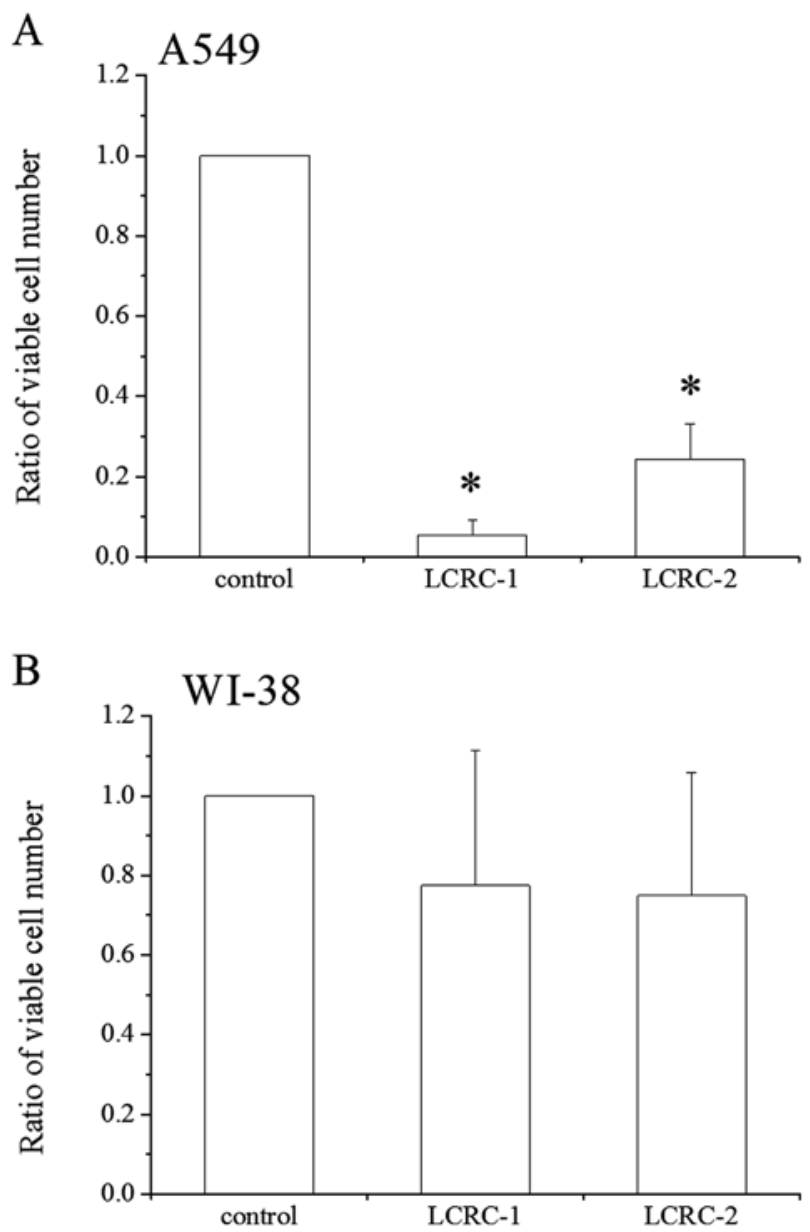

Figure 2. Effects of the liquid crystal-related compounds (LCRCs) on the growth of the A549 and WI-38 cells. The (A) A549 and (B) WI-38 cells cultured in the presence of $12 \mu \mathrm{M}$ of each compound for $72 \mathrm{~h}$ were harvested, and the viable cells were counted by trypan blue exclusion assay. The data are presented as the mean $\pm \mathrm{SD}$ of four independent experiments. ${ }^{*} \mathrm{p}<0.05$ by two-sided Mann-Whitney U test.

Clonogenic survival assay. The A549 cells were seeded onto a 60-mm culture dish (Iwaki) and incubated overnight to allow adherence to the dish. The compounds were added in culture medium $1 \mathrm{~h}$ before X-ray irradiation. Aluminum $(0.5 \mathrm{~mm})$ and copper $(0.3 \mathrm{~mm})$ filters at a distance of $45 \mathrm{~cm}$ from the focus were used to expose the cells to X-rays $(150 \mathrm{kVp}, 20 \mathrm{~mA})$ at a dose rate of $1.0 \mathrm{~Gy} / \mathrm{min}$ (MBR-1520R-3 Hitachi Medical Co., Tokyo, Japan) in the range of 1-8 Gy. The cells were cultured at $37^{\circ} \mathrm{C}$ in a humidified atmosphere containing $5 \% \mathrm{CO}_{2}$. After 7-day culture, the cells were fixed in methanol for $10 \mathrm{~min}$ at room temperature, air dried, and stained by Gimsa stain solution. The colonies consisting of more than 50 cells were counted by inversion microscopy.

Statistical analysis. The significance of differences between the control and experimental groups was determined by two-sided Student's t-test and two-sided Mann-Whitney U test depending on the data distribution. A one-way ANOVA model and the Tukey-Kramer test were used to analyze the data from multiple groups (i.e., Fig. 4D and E). The significance level was set to $\mathrm{p}<0.05$. Excel 2010 software (Microsoft, USA) with the add-in software Statcel 2 was used for statistical analysis (14).
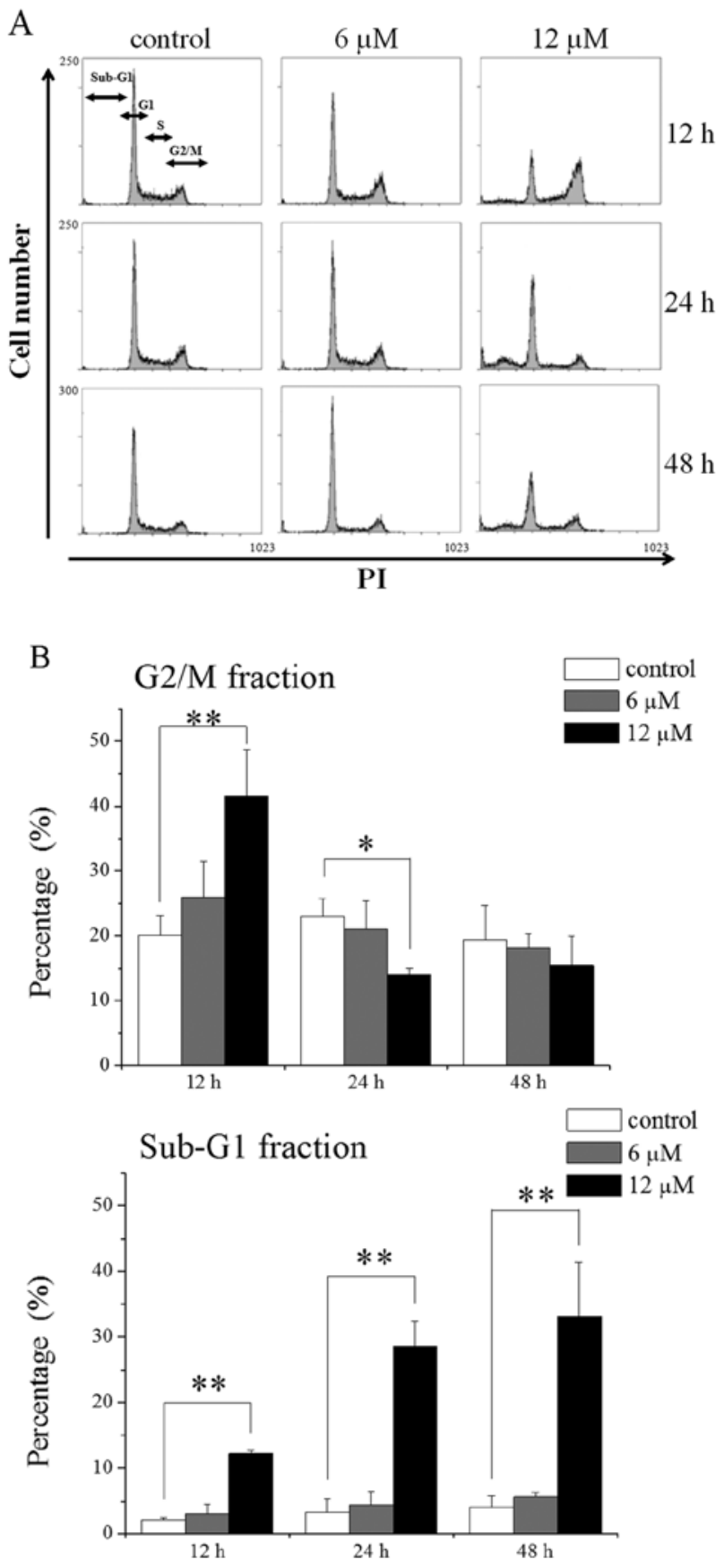

Figure 3. Effects of the liquid crystal-related compounds (LCRC-1) on the cell cycle in A549 cells. The A549 cells cultured in the presence of 6 and $12 \mu \mathrm{M}$ LCRC-1 for 12-48 $\mathrm{h}$ were harvested, and the cell cycle profile was analyzed by flow cytometry, as described in the Materials and methods section. (A) Representative histograms are shown. (B) The fractions of G2/M and sub-G1 phase are shown. The data are presented as the means \pm SD of four independent experiments. ${ }^{\mathrm{p}} \mathrm{p}<0.05$ by two-sided Student's t-test.

\section{Results}

LCRCs suppresses the growth of A549 cells. The suppressive effects of LCRCs, whose cell suppressive effect had been previously demonstrated in the K562 cells, were investigated in the NSCLC cell line A549 and in WI-38 normal fibroblasts. As shown in Fig. 2A, both LCRCs suppressed the growth of the A549 cells. The suppressive effects of LCRC-1 and 2 caused 95 and $78 \%$ inhibition, respectively. The effects of these 
A

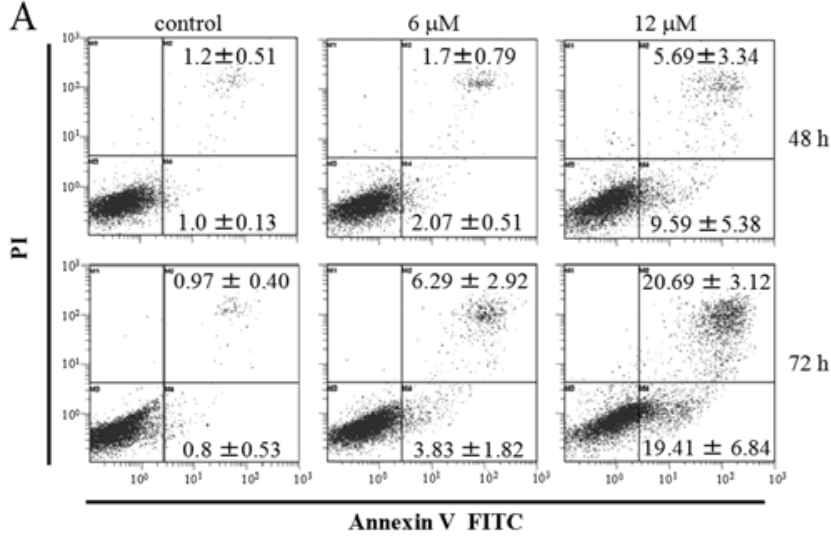

D

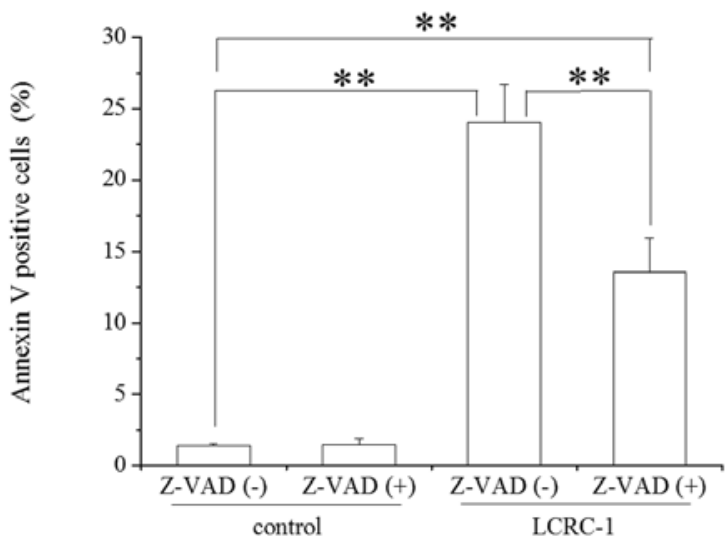

B

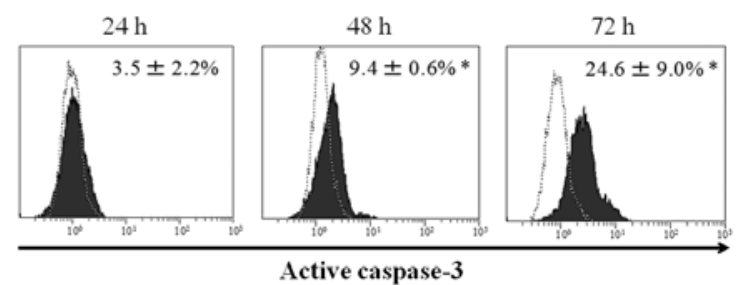

C

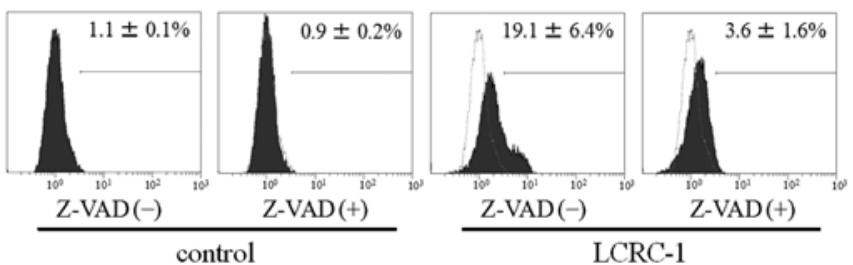

E

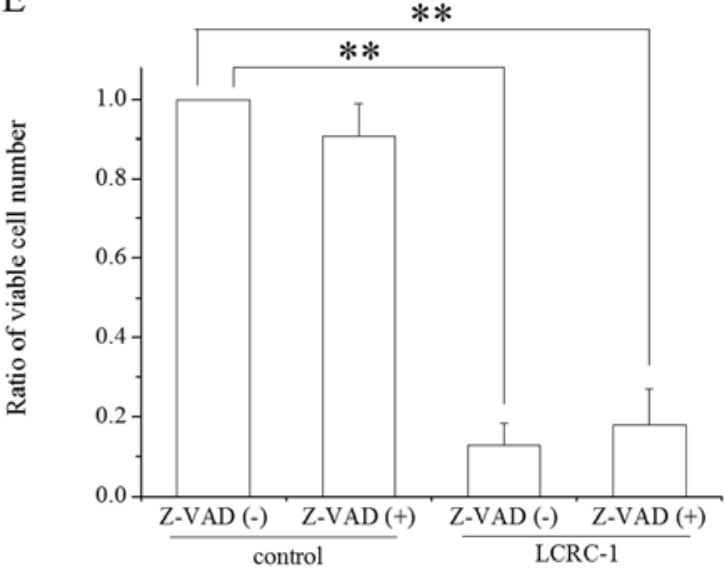

Figure 4. Effect of LCRC-1 on the induction of apoptosis in the A549 cells. The A549 cells cultured in the presence of 6 and $12 \mu \mathrm{M}$ LCRC-1 for 48 and $72 \mathrm{~h}$ were harvested, and the apoptotic cells were analyzed. (A) Annexin/PI staining was performed by flow cytometry, as described in the Materials and methods section. Representative histograms are shown, and the inset numbers are the percentage of Annexin(+)/PI(-) and Annexin(+)/PI(+) cells. The data are presented as the means \pm SD of four independent experiments. ${ }^{*} \mathrm{p}<0.05$ and ${ }^{* *} \mathrm{p}<0.01$ by two-sided Student's t-test, respectively. (B) The expression of active caspase-3 was analyzed by flow cytometry, as described in the Materials and methods section. Representative histograms are shown, and the inset numbers are the percentage of active caspase-3 positive cells. The expression of active caspase- 3 in the A549 cells treated with vehicle is shown as a dotted line. The data are presented as the mean \pm SD of four independent experiments. " $\mathrm{p}<0.05$ and ${ }^{* *} \mathrm{p}<0.01$ by two-sided Student's t-test, respectively. (C-E) The A549 cells preincubated with Z-VAD-FMK were cultured in the presence of $12 \mu \mathrm{M} \mathrm{LCRC}-1$ for $48 \mathrm{~h}$. The cells were harvested, followed by analysis of (C) active caspase-3, (D) annexin/PI staining and determination of the (E) viable cell number count. The data are presented as the mean \pm SD of three independent experiments. Z-VAD, Z-VAD-FMK; ${ }^{*}<<0.05$ by Tukey-Kramer test.

LCRCs on WI-38 proliferation were also examined. Although LCRCs slightly suppressed WI-38 proliferation, there was no statistically significant difference in suppression between the treatments with vehicle and LCRCs (Fig. 2B). These results indicate that the suppressive effect in the A549 cells was more dramatic for LCRC-1 than that for LCRC-2, whereas the effect of either compound was minimal to non-existent on growth of the WI-38 cells. Because the $50 \%$ inhibitory concentration $\left(\mathrm{IC}_{50}\right)$ of LCRC-1 for $72 \mathrm{~h}$ was $5.52 \pm 1.88 \mu \mathrm{M}$ (data not shown), we selected $6 \mu \mathrm{M}$ (approximately $\left.\mathrm{IC}_{50}\right)$ and $12 \mu \mathrm{M}\left(2 \times \mathrm{IC}_{50}\right)$ LCRC-1 concentrations for following experiments.

LCRC-1 induces G2/M arrest in the A549 cells. The effect of LCRC-1 on the cell cycle profile in the A549 cells was analyzed. The treatment with $12 \mu \mathrm{M}$ LCRC- 1 for $12 \mathrm{~h}$ significantly increased the $\mathrm{G} 2 / \mathrm{M}$ fraction compared with treatment with the control (Fig. 3A). The increase in the G2/M fraction caused by treatment with $12 \mu \mathrm{M}$ LCRC-1 disappeared at $24 \mathrm{~h}$, whereas the sub-G1 fraction, a hallmark of apoptosis, was increased (Fig. 3B). In contrast, no statistically significant difference in the cell cycle profiles was observed between the treatments with the control and $6 \mu \mathrm{M}$ LCRC-1.

LCRC-1 induces apoptosis in the A549 cells. Because the sub-G1 fraction was induced in the cells treated with $12 \mu \mathrm{M}$ LCRC-1, the analysis of apoptosis was performed in detail. First, Annexin V/PI staining methods were used to analyze the apoptosis induction. The percentages of the Annexin $\mathrm{V}(+) / \mathrm{PI}(-)$ cells with early apoptotic cells and Annexin $\mathrm{V}(+) / \mathrm{PI}(+)$ cells with late apoptotic cells were significantly higher in the cells treated with LCRC-1 for $72 \mathrm{~h}$ compared with those of the control (Fig. 4A). Although the treatment with LCRC-1 for $48 \mathrm{~h}$ also increased those fractions, no statistically significant difference was observed. To investigate in detail the induction of apoptosis by LCRC-1, the expression of active caspase-3, an executioner of apop- 
A

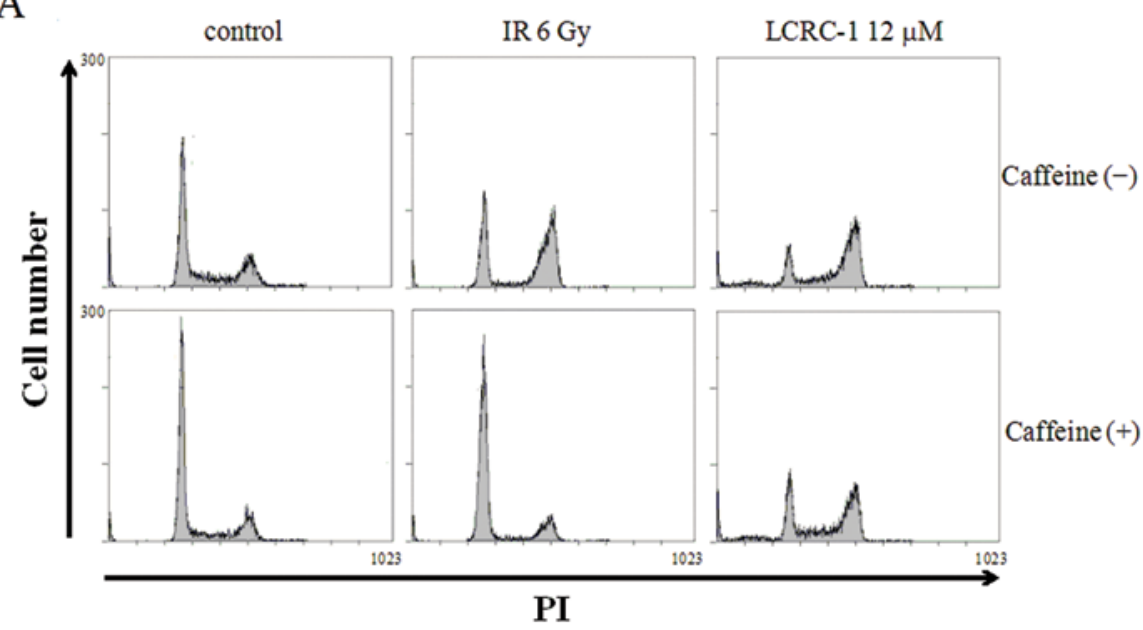

B
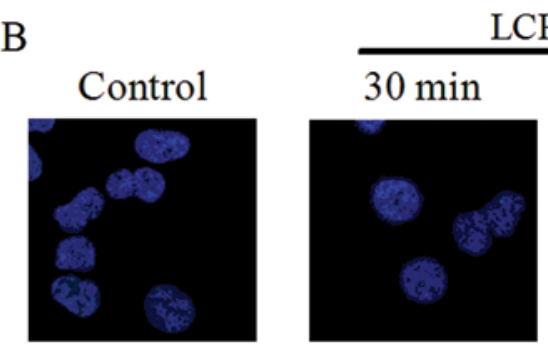

LCRC-1

Figure 5. Effect of LCRC-1 in causing DNA damage in the A549 cells. (A) The A549 cells preincubated with caffeine were cultured in the presence of $12 \mu$ M LCRC-1 for $12 \mathrm{~h}$. The cells were harvested and the cell cycle profile was analyzed. Representative histograms are shown. To prepare the positive-control cells, the cells were exposed to 6-Gy X-rays and harvested $12 \mathrm{~h}$ after irradiation. (B) The A549 cells cultured in the presence of $12 \mu \mathrm{M} \mathrm{LCRC}-1$ for 0.5 and $3 \mathrm{~h}$ were harvested and the expression of $\gamma$-H2AX was analyzed as described in the Materials and methods section. To prepare the positive-control cells, the cells were exposed to 6-Gy X-ray and harvested 30 min after irradiation. The nuclear and $\gamma$-H2AX staining were performed by DAPI (blue) and Alexa Fluor $488^{\circledR}$ (green), respectively.

tosis, was analyzed. Caspase-3 activation in the cells treated with $12 \mu \mathrm{M}$ LCRC-1 for 48 and $72 \mathrm{~h}$ was higher than that in the vehicle control (Fig. 4B). To clarify the involvement of caspase- 3 activation in the induction of apoptosis by LCRC-1, Z-VAD-FMK, a pan-caspase inhibitor, was used. Pretreatment with Z-VAD-FMK moderately inhibited caspase-3 activation by LCRC-1 (Fig. 4C) and reduced the percentage of Annexin positive cells in the cells treated with LCRC-1 (Fig. 4D). However, the reduction of cell number was not recovered by treatment with Z-VAD-FMK (Fig. 4E).

The effects of LCRC-1 in causing DNA damage. To investigate the mechanisms of $\mathrm{G} 2 / \mathrm{M}$ arrest by LCRC-1, we focused on DNA damage. Because ataxia telangiectasia mutated (ATM), which is one of the DNA damage-responsive kinases, activates $\mathrm{G} 2 / \mathrm{M}$ checkpoint arrest following DNA damage such as exposure to ionizing radiation (15), caffeine, as an ATM inhibitor, was used to investigate the involvement of ATM in $\mathrm{G} 2 / \mathrm{M}$ arrest by LCRC-1 (16). Pretreatment with caffeine completely inhibited $\mathrm{G} 2 / \mathrm{M}$ arrest by 6-Gy irradiation, whereas it hardly affected G2/M arrest by LCRC-1 (Fig. 5A). Furthermore, although the expression of $\gamma-\mathrm{H} 2 \mathrm{AX}$, a marker of DNA damage (17), was observed in 6-Gy irradiated cells prepared as positive controls, it was not observed in the cells treated with LCRC-1 at any time points $(0.5,3,24 \mathrm{~h})$ (Fig. 5B and data not shown).

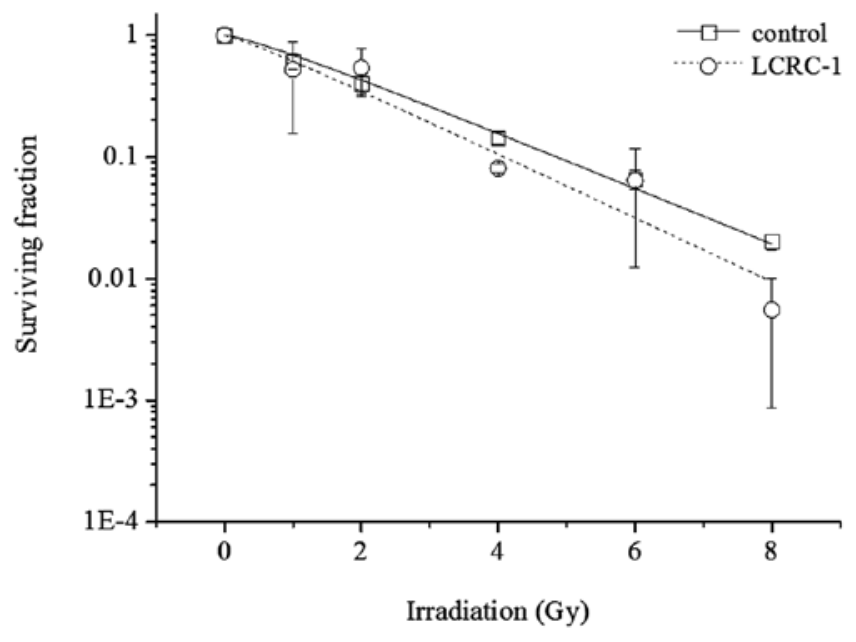

Figure 6. Radiosensitization effect of LCRC-1 in the A549 cells. The A549 cells preincubated with $6 \mu \mathrm{M} \mathrm{LCRC}-1$ for $1 \mathrm{~h}$ were exposed to 1-8 Gy X-rays. After 7 days of culture, the colonies consisting of more than 50 cells were counted. The data are expressed as the mean \pm SD of four independent experiments.

Radiosensitization effect of LCRC-1. The radiosensitization of LCRC-1 was examined. The survival curves of the A549 cells exposed to X-rays with or without $6 \mu \mathrm{M}$ LCRC-1 are shown in Fig. 6. Although LCRC-1 slightly enhanced radiosensitivity in the A549 cells, no statistically significant difference was observed. 


\section{Discussion}

In the present study, we demonstrated that LCRCs possessing three aromatic rings, whose potential to induce apoptosis had been previously demonstrated in human chronic myelogenous leukemia K562 cells (12), suppressed cell growth in human non-small cell lung cancer A549 cells (Fig. 2A). Takahashi et al previously reported that some amphiphilic LCCs such as cyanobiphenyl derivatives with a terminal hydroxyl and phenylpyrimidine derivatives possessing D-glucamine inhibited cell growth through G1-phase arrest in the A549 cells, although they did not induce cell death (11). However, LCRCs used in this study (particularly LCRC-1) increased the sub-G1 fraction and Annexin V-positive cells and activated caspase-3 in the A549 cells (Figs. 3, 4A and B), thus showing that LCRC-1 can induce apoptosis in the A549 cells. Furthermore, the increase of Annexin V-positive cells caused by LCRC-1 was partly inhibited by caspase inhibitor (Fig. 4D). This result indicates that LCRC-1 induced apoptosis through a caspase-dependent pathway. In contrast, the suppression of cell numbers by LCRC-1 did not recover after treatment with a caspase inhibitor (Fig. 3E); the probable reason for this is that the specific caspase inhibitor used may not prevent cell cycle arrest by LCRC-1.

ATM is a DNA damage sensor and activates the DNA repair process (18). Following exposure to DNA damage, including that caused by ionizing radiation, ATM activates G2/Mcheckpoint arrest. However, caffeine, an ATM inhibitor, hardly affected G2/M arrest by LCRC-1 (Fig. 5A). Furthermore, treatment with LCRC-1 did not induce the expression of $\gamma$-H2AX, a marker of DNA damage (Fig. 5B). Considering these results, it is not likely that LCRC-1 induces DNA damage and then results in G2/M arrest. On the other hand, c-Jun $\mathrm{N}$ terminal kinase (JNK) is involved in not only apoptosis but also cell cycle arrest (19). Furthermore, since Fukushi et al reported that LCRC-1 activated JNK in the K562 cells (12), there is a possibility that JNK is associated with suppression of LCRC-1 in the A549 cells. However, a JNK inhibitor VIII (Calbiochem ${ }^{\circledR}$ ) did not affect cell suppression by LCRC-1 in the A549 cells (data not shown). Therefore, other mechanisms such as endoplasmic reticulum stress may be involved in the suppressive effects of LCRC-1 (20).

Combination treatment of radiotherapy with chemotherapy such as cisplatin has been extensively used in the management of many types of solid malignancies including NSCLC $(21,22)$. Although, the radiosensitization effect of $6 \mu \mathrm{M}$ LCRC-1 was expected in the A549 cells, it hardly enhanced the radiosensitization (Fig. 6). However, LCRC-1 did not attenuate the effect of ionizing radiation at other concentrations $(1.5$ and $3 \mu \mathrm{M}$, data not shown). Therefore, the combination treatment of LCRC-1 with radiotherapy may be possible.

In conclusion, we demonstrated that an LCRC possessing three aromatic rings (LCRC-1) can potentially suppress cell growth through cell cycle arrest at the G2/M phase and induction of apoptosis in the A549 cells. Interestingly, LCRC-1 did not inhibit the proliferation of WI-38 normal fibroblasts (Fig. 1B). Although the mechanisms of cell growth suppression by LCRC-1 were not elucidated in the present study, the tumor-specific suppressive effect of LCRC-1 is attractive for development of chemotherapeutic drugs. Therefore, further studies regarding the molecular mechanisms and structureactivity relationship of LCRCs may lead to the development of tumor-specific and more powerful chemotherapeutic drugs.

\section{Acknowledgements}

This study received support from a grant for Hirosaki University Institutional Research (2011). This study was partly supported by KAKENHI, Grant-in-Aid for Young Scientists (B, No. 23791383 HY).

\section{References}

1. Tang N, Du G, Wang N, Liu C, Hang H and Liang W: Improving penetration in tumors with nanoassemblies of phospholipids and doxorubicin. J Natl Cancer Inst 99: 1004-1015, 2007.

2. Cheng JH, Hung CF, Yang SC, Wang JP, Won SJ and Lin CN: Synthesis and cytotoxic, anti-inflammatory, and anti-oxidant activities of 2',5'-dialkoxylchalcones as cancer chemopreventive agents. Bioorg Med Chem 16: 7270-7276, 2008.

3. Goel A, Prasad AK, Parmar VS, Ghosh B and Saini N: 7,8-Dihydroxy-4-methylcoumarin induces apoptosis of human lung adenocarcinoma cells by ROS-independent mitochondrial pathway through partial inhibition of FNK/MAPK signaling. FEBS Lett 581: 2447-2454, 2007.

4. Chou TC, Zhang X, Zhong ZY, Li Y, Feng L, Eng S, Myles DR, Johnson R, Wu N, Yin YI, Wilson RM and Danishefsky SJ: Therapeutic effect against human xenograft tumors in nude mice by the third generation microtubule stabilizing epothilones. Proc Natl Acad Sci USA 35: 13157-13162, 2008.

5. Park SY, Kim YM and Pyo H: Gefitinib radiosensitizes non-small cell lung cancer cells through inhibition of ataxia telangiectasia mutated. Mol Cancer 9: 222, 2010.

6. Santin AD, Hermonat PL, Ravaggi A, Bellone S, Roman J, Pecorelli S, Cannon M and Parham GP: Effects of concurrent cisplatinum administration during radiotherapy vs. radiotherapy alone on the immune function of patients with cancer of the uterine cervix. Int J Radiat Oncol Biol Phys 48: 997-1006, 2000.

7. Stevenson CL, Bennett DB and Lechuga-Ballesteros D: Pharmaceutical liquid crystals: the relevance of partially ordered systems. J Pharm Sci 94: 1861-1880, 2005.

8. Goodby JW, Görtz V, Cowling SJ, Mackenzie G, Martin P, Plusquellec D, Benvegnu T, Boullanger P, Lafont D, Queneau Y, Chambert $\mathrm{S}$ and Fitremann J: Thermotropic liquid crystalline glycolipids. Chem Soc Rev 36: 1971-2032, 2007.

9. Luk YY, Campbell SF, Abbott NL and Murphy CJ: Non-toxic thermotropic liquid crystals for use with mammalian cells. Liq Cryst 31: 611-621, 2004.

10. Cervin C, Vandoolaeghe P, Nistor C, Tiberg F and Johnsson M: A combined in vitro and in vivo study on the interactions between somatostatin and lipid-based liquid crystalline drug carriers and bilayers. Eur J Pharm Sci 36: 377-385, 2009.

11. Takahashi Y, Hazawa M, Takahashi K, Nishizawa A, Yoshizawa A and Kashiwakura I: Suppressive effects of liquid crystal compounds on the growth of the A549 human lung cancer cell line. Invest New Drugs 29: 659-665, 2011.

12. Fukushi Y, Hazawa M, Takahashi K, Yoshizawa A and Kashiwakura I: Liquid crystal-related compound-induced cell growth suppression and apoptosis in the chronic myelogenous leukemia K562 cell line. Invest New Drugs 29: 827-832, 2011.

13. Hannun YA: Apoptosis and the dilemma of cancer chemotherapy. Blood 89: 1845-1853, 1997.

14. Yanai H: Statcel - The useful add-in software forms on Excel. 2nd edition. OMS, Tokyo, 2006.

15. Shibata A, Barton O, Noon AT, Dahm K, Deckbar D, Goodarzi AA, Löbrich M and Jeggo PA: Role of ATM and the damage response mediator proteins 53BP1 and MDC1 in the maintenance of $\mathrm{G}(2) / \mathrm{M}$ checkpoint arrest. Mol Cell Biol 30: 3371-3383, 2010 .

16. Blasina A, Price BD, Turenne GA and McGowan $\mathrm{CH}$ : Caffeine inhibits the checkpoint kinase ATM. Curr Biol 9: 1135-1138, 1999.

17. Kuo LJ and Yang LX: Gamma-H2AX - a novel biomarker for DNA double-strand breaks. In Vivo 22: 305-309, 2008. 
18. Tomita M: Involvement of DNA-PK and ATM in radiationand heat-induced DNA damage recognition and apoptotic cell death. J Radiat Res 51: 493-501, 2010.

19. Cho SD, Li G, Hu H, Jiang C, Kang KS, Lee YS, Kim SH and $\mathrm{Lu} \mathrm{J}$ : Involvement of c-Jun N-terminal kinase in G2/M arrest and caspase-mediated apoptosis induced by sulforaphane in DU145 prostate cancer cells. Nutr Cancer 52: 213-224, 2005.

20. Bourougaa $K$, Naski N, Boularan C, Mlynarczyk C, Candeias MM, Marullo S and Fåhraeus R: Endoplasmic reticulum stress induces $\mathrm{G} 2$ cell-cycle arrest via mRNA translation of the p53 isoform p53/47. Mol Cell 38: 78-88, 2010.
21. Brattström D, Bergqvist M, Hesselius P, Wagenius G and Brodin O: Different fraction schedules and combinations with chemotherapy in radiation treatment of non-small cell lung cancer. Anticancer Res 20: 2087-2090, 2000.

22. Gupta S, Koru-Sengul T, Arnold SM, Devi GR, Mohiuddin M and Ahmed MM: Low-dose fractionated radiation potentiates the effects of cisplatin independent of the hyper-radiation sensitivity in human lung cancer cells. Mol Cancer Ther 10: 292-302, 2011. 